is scanty" and that "all observers are agreed" that Rockefeller insisted upon good wages and kindly treatment, that labour troubles were rare and that unions were discouraged.

No small part of Mr. Rockefeller's strength seems to have been his ability to select and retain highly gifted associates both in his business affairs and in the task of giving away five hundred million dollars. Almost ell were men of strong and independent minds, who accepted Mr. Rockefeller as primus inter pares rather than as their despotic head. Appropriately, much of Prof. Nevins's study is concerned with these men. His treatment of the parts they played and of their personalities and achieverments throws much light on Mr. Rockefeller's own qualities and his place in history. Even so, despite all that has been written by others and despite the illumination which Prof. Nevins has himself given, he is, probably, right to entitle his final chapter (in which he seeks conclusions on these questions) "Trial Balance", instead of "Epilogue", as in the earlier biography.

L. Farrer-Brown

\section{DICTIONARY OF CHEMISTRY}

The Van Nostrand Chemist's Dictionary

Edited by Prof. Jurgen M. Honig, Dr. Morris B. Jacobs, Prof. S. Z. Lewin, William R. Minrath, and Dr. George Murphy. Pp. iv +762. (New York: D. Van Nostrand Company, Inc.; London : Macmillan and Co., Ltd., 1954.) 60s. net.

7 HE decision what to exclude or include can 1 never be easy for the compilers of any specialized dictionary; without a clear conception of the users for whom the dictionary is intended, the task may be well-nigh impossible. This dictionary is well produced and printed, and it appears to be notably free from misprints-that of "Levenstein" for "Levinstein" is one of the very few which have been noted. Nevertheless, it is not easy to judge from the internal evidence exactly for whom this book is intended. The exclusion of all trade names, even those in the field of plastics and synthetic fibres coming into general use as generic terms, whether justifiable or not, severely limits its use for the technical or industrial chemist, who will find Bennett's "Concise Chemical and Technical Dictionary" more useful. The term 'rayon', for example, is omitted, and even the scientific or academic chemist might well look for definitions of the meaning of some such terms. There appears, moreover, to be no clear idea in the mind of the compilers as to what a chemist is likely to look for in such a dictionary as distinct, for example, from Lange's "Handbook of Chemistry" or "Atack's Chemists' Yearbook". So far as the British reader is concerned, American spelling and the American outlook, evident, for example, in the article on chemical nomenclature, quite as much as the high price, will tend to discourage its use. Whether a chemist would expect to find these articles in the dictionary may be a matter of opinion. He might at least have expected to find something more than a reprint or digest which ignores all contributions other than from American sources. Further, if nomenclature is introduced, why only six pages on chemical nomenclature in general, but twelve on carbohydrate nomenclature and none on other special aspects, such as that of co-ordination compounds, hydrogen isotopes, fluorine and phosphorus compounds?
A feature of the book is the large number of reactions and tests which are included under proper names. More than five thousand entries of this kind are claimed. For reactions, however, the book is less comprehensive than Wheeler and Adams's "Name Index" and, moreover, the latter has the advantage of references. The absence of references and almost complete absence of dates is a feature of this dictionary which from one point of view detracts considerably from its value. A few of the definitions appear shaky or inadequate, notably those of 'alembic', 'coupling' and 'antioxidant'. There is also a certain lack of balance: for example, the term 'cinnoline' is not defined, but 'cinnamate', 'cinnamic', 'cinnamoyl' and 'cinnamyl' are all elaborated.

Apart from the rather dubious omission of practically all terms verging on the category of a trade name, even where they may well be of interest to the academic chemist, omissions such as 'magneto chemistry', 'Raney-Nickel catalyst', 'fluorocarbon' and 'hydrogenolysis' are to be noted, as well as that of the antibiotics from penicillin onwards or medicinals such as 'cortisone', 'prontosil' and the like.

The layout of the dictionary is clear and even lavish. There would appear to be plenty of room for compression in this respect. Careful editing of such articles as those on benzene formulæ, the nomenclature of benzene substitution products, and some of the rather inexplicable entries multiplied under such prefixes as 'chloro-', 'phosphoro-' and 'thio-', etc., might well have reduced the size of the dictionary sufficiently for it to be produced at a price within the limits which a chemist in non-dollar countries could reasonably be expected to pay.

R. BRIGHTMAN

\section{FRAMEWORK OF THE SOCIAL SCIENCES}

The Tools of Social Science

By John Madge. Pp. $x+308$. (London, New York and Toronto : Longmans, Green and Co., Ltd., 1953.) 25s. net.

THIS is a very valuable book; but it will be a difficult one for the student or the general reader. It is, in fact, two books in one. Its objective is to provide an account of the methods which the social scientist has developed during the past hundred years in the prosecution of social researches ; but the author has found it impossible to confine himself to a mere description of methods, as such. The dilemma in which he has found himself is that the conceptual framework within which the social sciences have grown is by no means secure. There are serious gaps in it, and, to pursue the analogy further, parts of the structure are in a state of severe tension. Since the conceptual framework is so inadequate, the secondary or methodological system associated with it is hard to describe; it is still harder to evaluate it. The author has therefore found himself, quite consciously, trying to write a book on the logic of the social sciences and another on their methods at one and the same time.

The parts of the book dealing with logic are so good that one can only hope that when Mr. Madge produces the second edition of his work he will display the courage of his convictions, and re-write it as a treatise entirely devoted to a critical analysis of the 